\title{
Effect of Hydrazine on Aconitine-Induced Atrial Tachycardia in the Rabbit
}

\author{
Tsunetaka MAтовA, M.D.
}

\section{SUMmary}

Except positive inotropic action, hydrazine has been detected to have negative chronotropic and dromotropic actions in the rabbit's atrial and bullfrog's ventricular muscles. Aconitine-induced atrial tachycardia in rabbits and spontaneously beating ventricular tachycardia in bullfrogs were promptly converted to bradycardia by hydrazine. The mechanisms of these actions of hydrazine were concluded to result from (1) a prolonged refractory period, (2) a suppression in automaticity, (3) the increase of threshold, and (4) the delayed conduction velocity.

\section{Additional lndexing Words:}

Chronotropic action Dromotropic action Refractory period Ventricular automaticity Threshold Conduction velocity Bullfrog ventricular muscles

$\mathrm{I}^{\mathrm{N}}$ $\mathrm{N}$ the clinical field there have been used several antiarrhythmic agents such as quinidine, procaine amide, the local anesthetic agents, the beta adrenergic blocking drugs and so on. The mechanisms of their actions have been investigated from the electrophysiological viewpoint. ${ }^{1{ }^{1,2)}}$

A low concentration of hydrazine has negative chronotropic and dromotropic actions on amphibian and mammalian cardiac muscles in our observations. Aconitine has been described to produce tachycardia with irregularity of the cardiac muscles in the form of fiutter or fibrillation, resulting from enhancing the oscillatory potential of the cell and accelerating the spontaneous slow depolarization in the pacemaker cell. ${ }^{3-5}$ ) Since then this agent has been used to study the mechanism of fibrillation.

The purpose of this paper is to clarify electrophysiologically the mode of the negative chronotropic and dromotropic actions of hydrazine in the aconitine-induced atrial tachycardia of rabbit and the spontaneous ventricular tachycardia of bullfrog.

From the Department of Physiology, Kurume University School of Medicine, Kurume 830.

This study was in part supported by Scientific Research Grant from the Ministry of Education.

Received for publication February 5, 1973. 


\section{METHODS}

The general procedures of experiments and the experimental apparatus except a modified flow set were the same as described in the previous paper. ${ }^{6,7)}$

The preparation, dissected from the atria of rabbit under the anesthesia of ether, was bathed in Tyrode's solution bubbled with $100 \%$ of oxygen, which resulted in a $\mathrm{pH}$ of 7.3 to 7.4. A continuous stream of the Tyrode's solution was kept at a constant temperature of $36 \pm 1^{\circ} \mathrm{C}$ during the experiments. The tissue was driven by submaximal electrical stimulation through a $2 \mathrm{M} \mathrm{NaCl}$ capillary microelectrode (approximately $1 \mathrm{megohm}$ ) in a constant rate of $120 / \mathrm{min}$. The resistance of glass-capillary microelectrode was 12 to 20 megohm.

Aconitine-induced atrial tachycardia in the rabbit was produced in the following procedures; aconitine, $1-5 \mu \mathrm{g} / \mathrm{ml}$, was applied to the perfusing solution under the conditions that the streaming solution was halted for about $10 \mathrm{~min}$. After these treatments, the perfusing flow was resumed. After then atrial tachycardia occurred and electrical stimulation $(120 / \mathrm{min})$ was put off. The aconitine-induced atrial tachycardia did not disappear more than approximately one hour. The aconitine-induced atrial tachycardia was observed on intracellular action potential changes, employing a conventional microelectrode technique.

Spontaneous tachycardia of ventricular strips, isolated from bullfrog (Rana catesbiana), were also observed on the changes of twitch contractions by means of a force-displacement transducer.

The dose of hydrazine which could convert the aconitine-induced atrial tachycardia to bradycardia in the rabbit was 2 to $5 \mathrm{mM}$. Whereas, for the ventricular tachycardia in the bullfrog, 7 to $20 \mathrm{mM}$ of hydrazine was administered.

The Tyrode's solution had the following composition in $\mathrm{mMol} / \mathrm{L}: \mathrm{NaCl}, 147$; $\mathrm{KCl}, 2.68 ; \mathrm{CaCl}_{2}, \mathrm{I.8} ; \mathrm{MgCl}_{2}, 0.49 ; \mathrm{NaH}_{2} \mathrm{PO}_{4}, 3.3$ and glucose, 5.6 with $60 \mathrm{ml}$ of $0.1 \mathrm{M}$ sodium phosphate solution as buffer. The composition of Ringer's solution and the procedure of adjustment of hydrazine solution were the same as described previously. $\left.{ }^{6}\right)$ (Wako).

The drugs used were Aconitine Amorphous (Sigma) and Hydrazine Hydrate

All experiments were carried out at room temperature $\left(22-24^{\circ} \mathrm{C}\right)$.

\section{RESULTS}

1. Effect of hydrazine on aconitine-induced atrial tachycardia in the rabbit

Typical aconitine-induced atrial tachycardia in the form of fibrillation or flutter was illustrated in the record 1 of Fig. 1, of which irregular rhythms were recorded using a conventional microelectrode technique. The rate of the beats was about 300 per minute. This tachycardia with irregularity was usually maintained over a period of $60 \mathrm{~min}$. Three to $5 \mathrm{mM}$ of hydrazine added to the perfusing bath where the atrial strip was located, was able to convert this tachycardia to a slower rate of approximately 50 per minute within 7 min (records 2, 3, and 4). Removal of hydrazine by washing out of Tyrode's 


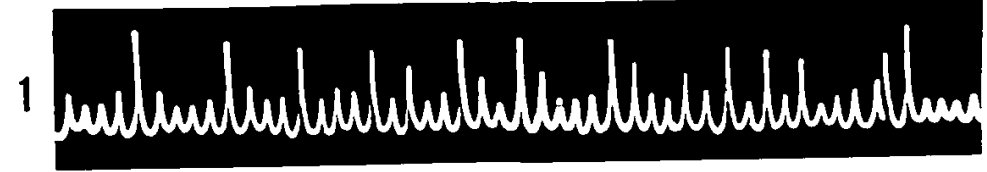

2
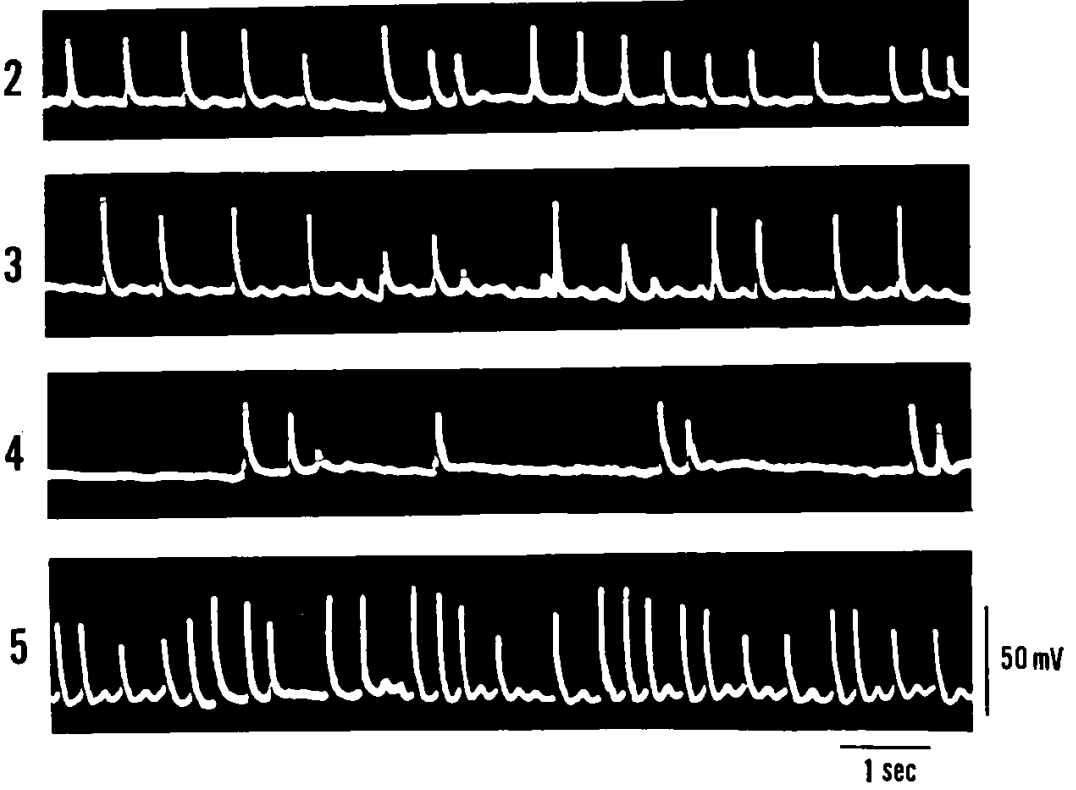

Fig. 1. Effect of hydrazine on the aconitine-induced atrial tachycardia in the rabbit, which is observed by intracellular action potentials. Record 1 shows the atrial tachycardia produced by $3 \mu \mathrm{g} / \mathrm{ml}$ of aconitine. The rate of the beats is about 300 per minute. By applying $5 \mathrm{mM}$ of hydrazine, it is decreasing to approximately 50 per minute; records 2,3 , and 4 show 3,5 , and $7 \mathrm{~min}$ after the addition of hydrazine, respectively. The washing out of Tyrode's solution causes an increase in the rate of beats in the atrial tachycardia; record 5 exhibits $15 \mathrm{~min}$ after the removal.

solution caused the irregular beats to accelerate and attain to the frequency of the initial (record 5). The amplitude of action potential became higher than that obtained before the application of hydrazine. When the higher dose of hydrazine (more than $10 \mathrm{mM}$ ) was administered, the action potentials were rapidly diminished, not to be recovered. Thus hydrazine was able to prolong the effective refractory period and to convert the aconitine-induced atrial tachycardia to a slower rate of the beats, of which actions were reversible.

2. Effect of hydrazine on a spontaneously beating ventricular tachycardia in the bullfrog

Spontaneous beatings with the rate of $0.9 \mathrm{cps}$ were obtained from a ventricular strip, isolated from a bullfrog, in Ringer's solution. These phenomena were observed by means of a force-displacement transducer in order to measure isometric twitch contractions. When 7 to $20 \mathrm{mM}$ of hydrazine was admin- 

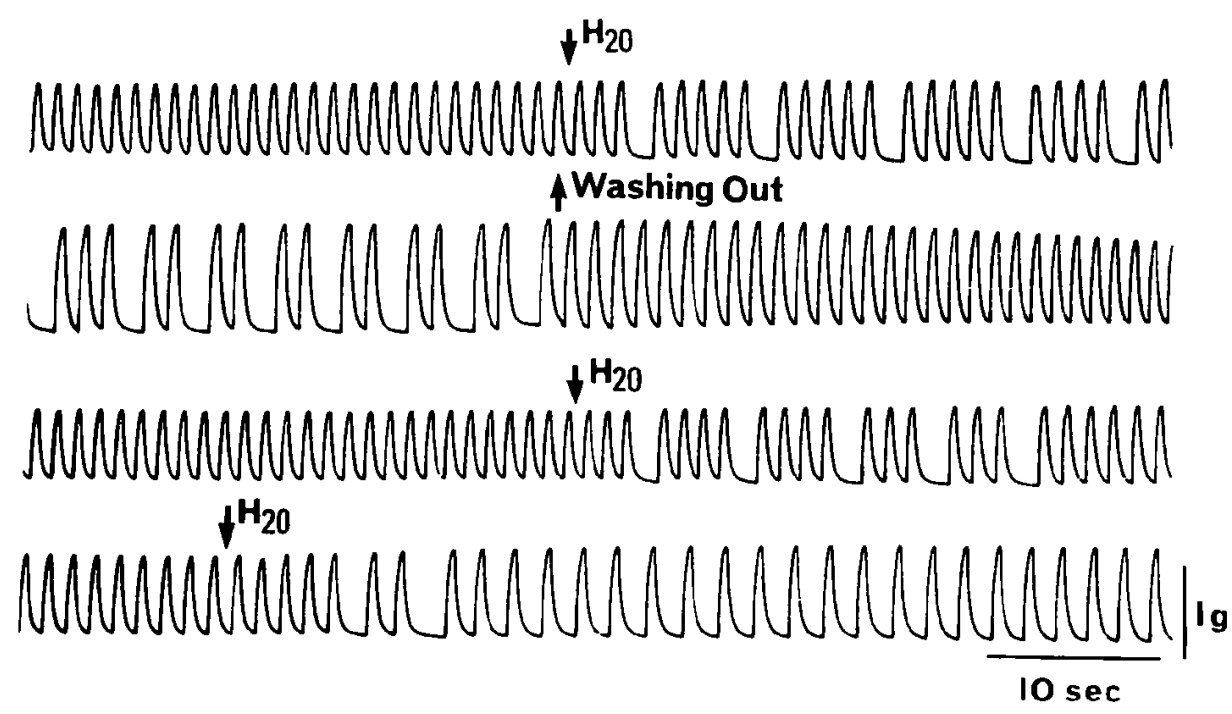

Fig. 2. Effect of hydrazine on tachycardia of a spontaneously beating ventricular strip. The tracings of this figure are continuously recorded. The rate of spontaneous beating is $0.2 \mathrm{cps}$ in Ringer's solution (the most upper trace). When $20 \mathrm{mM}$ hydrazine $\left(\mathrm{H}_{20}\right)$ is administered in the bathing solution, there appear a slower and irregular rate of beating $(0.5 \mathrm{cps})$ and an increase in the height of twitches (2nd trace). The washing out of the strip by Ringer's solution make the rate of the beatings accelerated, and the development of the twitches returned to the initial level (3rd trace). The repeated administrations of hydrazine produce the slower rate and the higher height of twitches (the last trace).

istered in the bathing solution, there appeared a slower and irregular rhythm with the rate of less than 0.5 cps. Moreover, these actions were associated with an increasing height of the twitch contraction.

The washing out of the strip by Ringer's solution made the rate of the twitches accelerated and the development of the twitch contraction returned to the initial level. The repeated administration of hydrazine induced the slower rate and the higher amplitude of twitches; namely, a reversible phenomenon. Thus hydrazine acted on the bullfrog's ventricular strips to suppress the ventricular automaticity and increase the contractile force.

3. Effects of hydrazine on the atrial muscle of the rabbit

An isolated muscle strip from the rabbit's atria was soaked in Tyrode's solution, oxygenating with $100 \%$ oxygen. Action potential, generated by suprathreshold electrical stimulation was exhibited in the record 1 of Fig. 4; the amplitude and the duration of action potential were approximately $85 \mathrm{mV}$ and $110 \mathrm{msec}$, respectively. With hydrazine of $3 \mathrm{mM}$ concentration, the action potential led on a distinguished configuration associated with a decrease in the amplitude and the duration of action potentials, and a slurring plateau. 


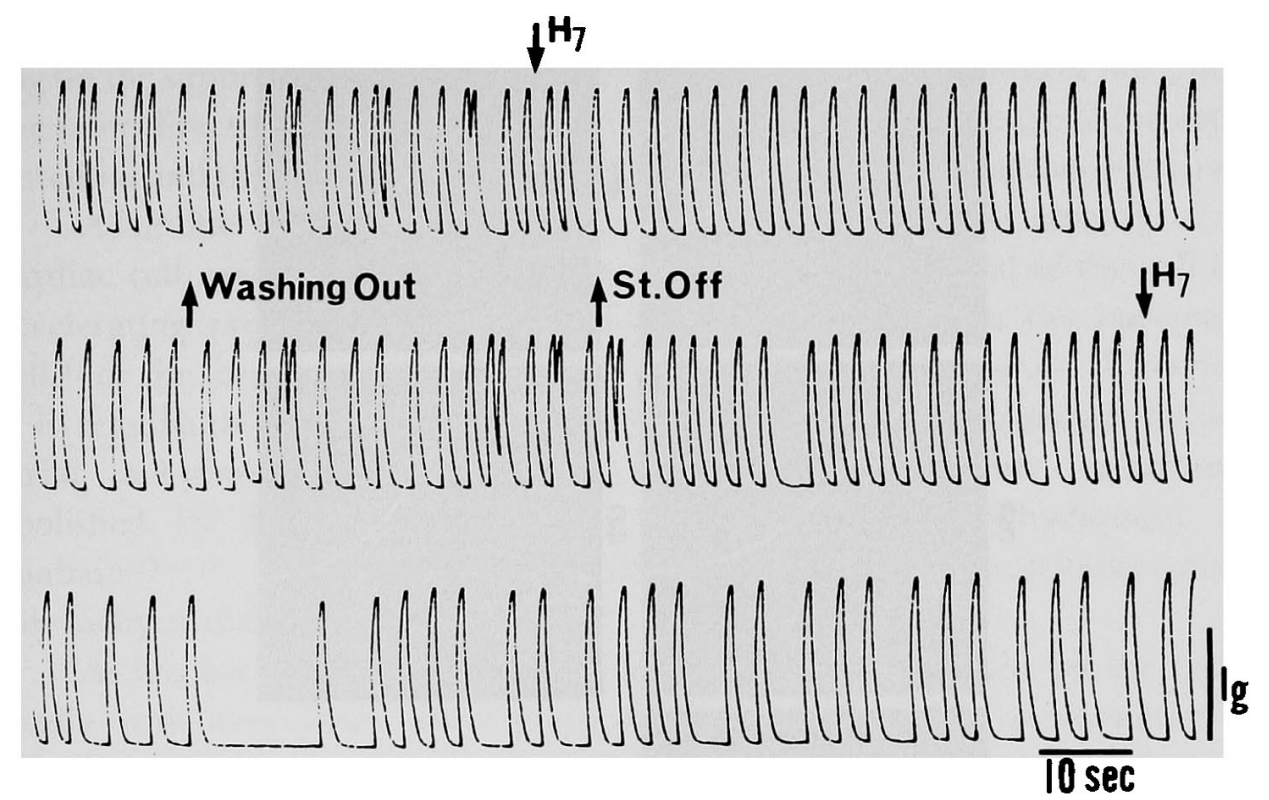

Fig. 3. The effect of hydrazine on a spontaneous arrhythmia of an electrically beating ventricular strip. The tracings of this figure are continuously recorded. The twitches driven by an electrical stimulation had frequent extrasystoles, which are completely extracted by the administration of $7 \mathrm{mM}$ hydrazine $\left(\mathrm{H}_{7}\right)$ as shown in the upper trace. When the strip is washed out by Ringer's solution (Washing Out), the extrasystoles appear again (middle trace). As an electrical stimulation is taken off (St. Off), this appears a spontaneous beating associated with irregular activities. The administration of $7 \mathrm{mM}$ hydrazine leads to decrease the rate of beating with irregularity and to increase the height of twitches under these conditions (lower trace).

Ten min after the administration of hydrazine, the threshold was increased, showing strengthening stimulation, and the conduction velocity was also delayed as illustrated in the records 2 and 3 . The washing out of Tyrode's solution induced the action potentials to recover (records 4 and 5). However, the conduction velocity has not been recovered until $10 \mathrm{~min}$ after the washing out.

\section{Discussion}

Nowadays, there have been several antiarrhythmic agents in common use, most of those including quinidine, procaine amide, the local anesthetic agents such as Xylocaine ${ }^{\circledR}$, antihistaminics and beta adrenergic blocking drugs with direct actions on the single cardiac cells.1,2) The electrophysiologic and clinical investigations on their effects have been made since their syntheses.

As already stated in the results, this study indicates that hydrazine con- 

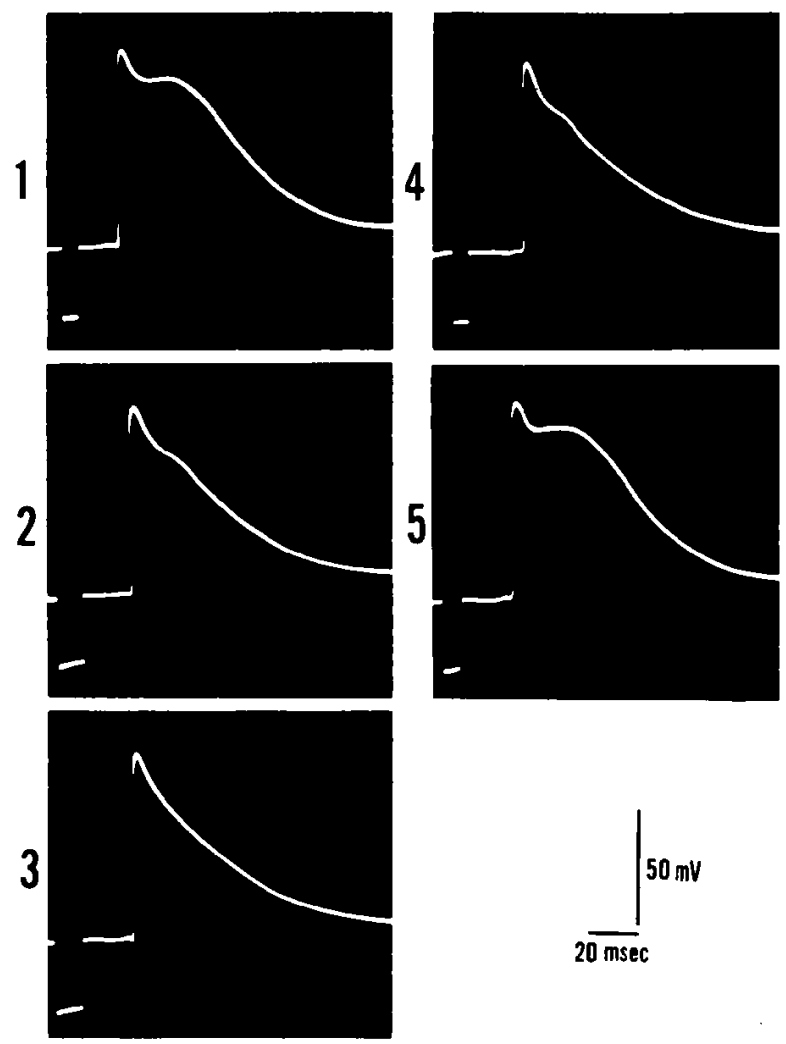

Fig. 4. Influence of hydrazine on the threshold and the conduction velocity in the rabbit's atrial muscles. Action potential in Tyrode's solution is generated by suprathreshold electrical stimulation (record 1). The addition of hydrazine induces various changes in the electrical responses of the tissues; an increase in the threshold, a decrease in the conduction velocity and the amplitude of action potential, and a slurring plateau phase. Records 2 and 3 show the changes of action potentials 5 and $10 \mathrm{~min}$ after applying $3 \mathrm{mM}$ of hydrazine. By washing out of Tyrode's solution, the shape of action potential and excitability are recovered (records 4 and 5).

version of amphibian or mammalian cardiac tachycardias could be considered to be due to a prolonged refractory period, a suppression in automaticity, the increase of threshold and the delayed conduction velocity.

The direct effects of hydrazine on membrane potentials in atrial and ventricular muscle fibers were manifested as a decrease in the maximum rate of rise of action potential, lowering resting potential, slurring plateaus phase and shortening of action potential duration. ${ }^{6}$ These actions of hydrazine resemble quinidine and procaine amide except the duration of action potential and resting potential. ${ }^{\mathbf{8}-\mathbf{1 0})}$ The result of lowering resting potential has been at variance or consistence with the data reported in different sites of cardiac muscle cells and the concentration of the drug. ${ }^{8)-13}$ ) The membrane respon- 
siveness curve is shifted to the right by quinidine and procaine amide, ${ }^{1,13}$ ) leading on the suppression of refractory period. ${ }^{8), 14}$ Hydrazine induces this shift to the same direction, as well. The decreasing maximum rate of rise of the action potential and the reduced excitability cause a decrease in conduction velocity. ${ }^{10}$ )

Aconitine produces ectopic, spontaneous and repetitive activity of the cardiac cell, resulting from enhancing the oscillatory potential of the cell and accelerating progressively the spontaneous slow potential in the pacemaker cell, ${ }^{4)}$ or the formation of local blocks and ectopic pacemakers. ${ }^{5)}$ Therefore, it is reasonable that hydrazine is able to reliably convert aconitine-induced atrial tachycardias. Aconitine-induced tachycardia is only occasionally abolished by quinidine, pronethalol, propranolol diphenylhydantoin and ouabain. ${ }^{14-16)}$ However, quinidine and procaine amide do not reliably convert this tachycardia. $\left.{ }^{15}\right), 17$ )

As has been discussed, the suppressive effects of hydrazine on the tachycardia with irregularity are explained by the results of a prolongation of effective refractory period, a suppression in automaticity and excitability, and delayed conduction velocity. In other words, hydrazine has negative chronotropic and dromotropic actions. Therefore, the mode of actions of hydrazine on tachycardias may be considered to be quinidine-like actions, except for stronger positive inotropic action. The mode of the positive inotropic action of hydrazine has already been mentioned in our previous paper. ${ }^{6}$ )

If further investigations in various regions of the conduction system of the heart and in the in situ hearts are made from the viewpoints of pharmacology and toxicology, hydrazine could be available as a so-called antiarrhythmics in the therapeutic field.

\section{AGKNOWLEDGEMENT}

The author is grateful to Prof. K. Koketsu for his helpful comments in this paper.

\section{REFERENCES}

1. Gettes LS: Am J Cardiol 28: 526, 1971

2. Singer DH: Electrical Activity of the Heart, ed by Manning GW, et al, Charles C Thomas, Illinois, 163, 1969

3. Scherf D: Proc Soc Exp Biol Med 64: 233, 1947

4. Matsuda K, Hoshi T, Kameyama S: Jap J Physiol 9: 419, 1959

5. Goto M, Tamai T, Yanaga T: Jap J Physiol 13: 196, 1963

6. Matoba T: Jap Heart J 14: 257, 1973

7. Matoba T: Jap Circulat J 31: 1833, 1967

8. Hoffman BF, Cranefield PF: Electrophysiology of the heart, McGraw-Hill, New York, 195, 1960 
9. West TC, Amory DW: J Pharmacol Exp Ther 130: 183, 1960

10. Singer DH, Lazzara R, Hoffman BF: Circulat Res 21: 537,1967

11. Coraboeuf E, Boistel J, Distel R: Compt rend acad sci Paris 242: 1225, 1956

12. Hoffman BF: Prog Cardiovas Dis 8: 319,1966

13. Weidmann S: J Physiol 129: 568, 1955b

14. Helfant RH, Scherlag BJ, Domato AN: Circulation 36: 108, 1967

15. Byrne JE, Dresel PE: J Pharmacol 48: 90, 1970

16. Lipicky RJ, Donoven TJ, Traycoff RB: Life Sci Part I 10: 1021, 1971

17. Brown BB, Acheson GH: J Pharmacol Exp Ther 102: 200, 1951 